\title{
Desafios do ensino de história
}

\section{Challenges facing history teaching}

Marieta de Moraes Ferreira

Renato Franco

Recentemente, debates em torno da produção de material didático agitaram a imprensa nacional. O jornalista Ali Kamel, em artigo incisivo publicado no jornal $O$ Globo em 18 de setembro de 2007, procurou mostrar a ideologização do livro Nova história crítica, de Mário Schmidt, comprado em larga escala pelo MEC para distribuição aos alunos da rede pública de ensino. Segundo as considerações de Kamel, o livro trazia graves incorreções, fornecendo uma visão distorcida, excessivamente unilateral da história: "querem fazer crer que o capitalismo é mau e a solução para tudo é o socialismo". Dois dias depois, na esteira de Kamel, surgiram argumentações de que o ardil socialista contido nos livros didáticos de história estaria diretamente ligado à formação da esquerda brasileira, que, embora já integrada ao capitalismo, insiste muitas vezes em impor como meta o ideário arcaico do socialismo. ${ }^{1}$

Marieta de Moraes Ferreira é doutora em história, professora do Departamento de História da Universidade Federal do Rio de Janeiro - UFRJ, professora e pesquisadora do CPDOC-FGV e coordenadora do FGV-Ensino Médio (marieta.moraes@ fgv.br). Renato Franco é doutorando em história na Universidade de São Paulo - USP e pesquisador do FGV-Ensino Médio (renato.franco@fgv.br).

Artigo recebido em 13 de março e aprovado para publicação em 13 de maio de 2008.

Estudos Históricos, Rio de Janeiro, vol. 21, nº 41, janeiro-junho de 2008, p. 79-93. 
Esse foi o estopim para uma acirrada discussão sobre a formação dos alunos e a produção de material didático - é importante destacar que boa parte dos debates sobre o mérito ou demérito dos livros envolveu jornalistas. De toda forma, a discussão trouxe à tona questões latentes no ensino da história No horizonte da produção dos livros didáticos e das discussões na imprensa apareceram duas variáveis fundamentais para nossa análise: em primeiro lugar, a dimensão econômica, que envolve altas cifras e grande número de editoras ávidas por vender seus produtos, e em segundo lugar, o controle da história a ser contada nos livros.

\section{"Histórias" em disputa?}

Atualmente, a rede pública adquire seus livros didáticos através do Programa Nacional do Livro Didático (PNLD), do MEC, seja para o ensino fundamental, seja para o ensino médio - neste último caso, trata-se do Programa Nacional do Livro Didático para o Ensino Médio (PNLEM). A cada três anos os livros são apresentados pelas editoras, são analisados por pareceristas da área designados pelo PNLD e, quando são aceitos, passam a constar do Guia de livros didáticos. Nele os professores da rede pública escolhem o livro que adotarão no próximo ciclo de três anos, e o Fundo Nacional de Desenvolvimento da Educação (FNDE) negocia a compra com as editoras. No ensino fundamental, cada aluno tem direito anualmente a livros de língua portuguesa, matemática, ciências, história e geografia; no ensino médio, a livros de língua portuguesa, matemática, história, biologia, química, geografia (a partir de 2008) e física (a partir de 2008).

Parece claro que as discussões travadas na imprensa não tinham fundamentos puramente ideológicos. Mesmo assim, não deixa de ser notável a matéria publicada pela revista Época em 24 de setembro de 2007, na qual se analisam alguns trechos e "falhas" do livro de Mário Schmidt. A disputa pelo discurso "verdadeiro" da história assume um tom retórico na seção "Ensino tendencioso", em que trechos do livro de Schmidt são utilizados para indicar "o que falta dizer" sobre determinados temas. Segundo a matéria, o livro trataria de forma parcial assuntos como a revolução cubana, o fim do comunismo, o liberalismo, o capitalismo. Esse julgamento, do qual os historiadores profissionais foram alijados, traz à baila o grande desafio da produção de material didático: o que devemos ensinar às nossas crianças? $\mathrm{E}$ como?

Ainda que o problema da ideologização contida no livro Nova história crítica seja relevante, é importante destacar que vários livros como este passaram incólumes durante os anos 1980, legitimados por uma produção historiográfica 
acadêmica igualmente marxista. A questão a ser perseguida não parece ser a busca do "verdadeiro" e do "falso" no livro de Schmidt. O problema do livro didático tem raízes muito mais profundas do que a simples defesa ou condenação de obras isoladas. Um dos principais desafios está justamente em fazer esse tipo de livro acompanhar as reinterpretações do passado feitas pelos historiadores acadêmicos. O constante diálogo en tre passado e presente, inerente a qualquer reflexão histórica, deve também ser estendido aos livros didáticos, sob pena de termos grandes hiatos entre o que se discute na academia e o que se ensina nas escolas do país.

Célia Cristina de Figueiredo Cassiano, em sua tese de doutorado, procura mostrar como, nos primeiros anos do PNLD, criado em 1985, os manuais escolhidos pelos professores eram em sua maioria reprovados pela equipe de avaliação do MEC (Cassiano, 2007: 71-77). Esse descompasso entre o que o MEC julgava aceitável e os materiais que os professores escolhiam constituiu um grande problema que começou a ser controlado a partir de 1996, ano em que saiu o primeiro Guia de livros didáticos, uma lista de livros aprovados na qual os professores deveriam escolher os manuais a serem adotados. Juntamente com o Guia, o MEC também passou a fornecer diretrizes pelas quais os livros deveriam se orientar: os Parâmetros Curriculares Nacionais (PCNs). Essas tentativas de fiscalização buscavam melhorar o crivo na escolha dos materiais e também legitimar, através da ação estatal, os direcionamentos dados ao PNLD a partir de 1996 (Cassiano, 2007). Essa seleção “oficial”, embora tenha criado um padrão qualitativo para a feitura dos materiais, ainda está longe de produzir livros que atendam aos requisitos de qualidade desejáveis do ponto de vista historiográfico.

Para além desses problemas intrínsecos às obras, há que se levar em conta também a pressão feita pelas editoras, o que pode influenciar na escolha dos livros. Com grandes esquemas de distribuição, as empresas mais bem estruturadas têm vantagens sobre as menores. É importante destacar ainda que, não obstante as tentativas de universalização dos materiais didáticos, o PNLD continua a apresentar problemas estruturais. Muitas escolas não recebem os livros escolhidos, e outras sequer recebem livros (Miranda e Luca, 2004: 128).

Após a adoção do Guia e dos PCNs, tendeu-se, via de regra, a uniformizar os conteúdos e a linguagem utilizada nos livros, que deveriam preencher certos requisitos considerados fundamentais (teórico-metodológicos, curriculares, de competências a serem desenvolvidas). Visões negativas sobre minorias, afro-descendentes, indígenas, foram terminantemente abolidas dos livros (Cassiano, 2007: 79). Contudo, a utilização de uma linguagem "politicamente correta" não resolve o que nos parece ser um grave e recorrente erro, qual seja, o de apresentar versões caricaturais sobre o passado. O controle da utilização de termos, e mesmo de determinadas interpretações, garantiu a produção de materiais 
corretos do ponto de vista da linguagem - avessos a preconceitos, refratários à discriminação -, mas não impediu a produção de materiais irregulares do ponto de vista historiográfico. Em suma, obras "politicamente corretas" não são necessariamente "bons livros" de história.

A produção de materiais "atualizados" requer, por outro lado, programas de atualização de professores para sua eficaz utilização. Esse diálogo entre academia e produção de materiais didáticos precisa ser bem estreitado, sob pena de reproduzirmos uma espécie de divórcio que se delineia entre dois setores de uma mesma matriz do conhecimento: o da história dita "científica" e o da história dos manuais escolares. $\mathrm{O}$ desinteresse da academia pela produção de didáticos e a incúria de grande parte dos que tradicionalmente se encarregam dessa tarefa reafirmam o quadro preocupante.

\section{O mercado de livros didáticos}

O MEC/FNDE é um grande comprador de livros didáticos. Em 2007, seu orçamento para a compra desse tipo e material era de 900 milhões de reais e estava dividido entre os seguintes programas:

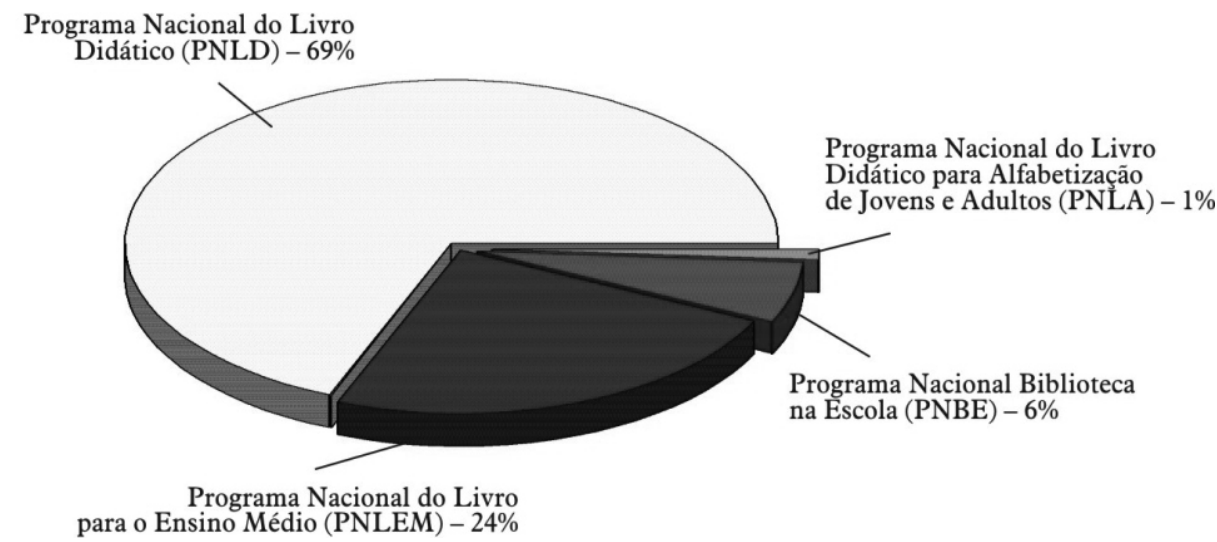

Fonte: Cassiano, 2007: 89.

A hipertrofia do segmento didático é evidente quando se observa sua representatividade no mercado brasileiro como um todo. 
Faturamento do mercado por setor editorial 2005/2006

\begin{tabular}{|c|c|c|}
\hline \multirow{2}{*}{ Setor } & \multicolumn{2}{|c|}{ Faturamento $(\mathrm{R} \$)$} \\
\hline & 2005 & 2006 \\
\hline Didáticos & $945.548 .907,21$ & $872.137 .954,60$ \\
\hline Obras gerais & $562.502 .252,70$ & $615.917 .103,26$ \\
\hline Religiosos & $231.291 .140,26$ & $242.138 .755,91$ \\
\hline Científicos, técnicos e profissionais & $384.696 .545,33$ & $418.550 .460,26$ \\
\hline Total & 2.124.138.845,50 & $2.148 .744 .274,03$ \\
\hline
\end{tabular}

Fonte: Câmara Brasileira do Livro, relatório de julho de 2007

Em 2006, a venda de livros didáticos correspondia a cerca de $41 \%$ de todo o mercado de livros do Brasil. Trata-se, portanto, de um mercado altamente lucrativo, com forte tendência à concentração em grandes empresas. Em 2007, os grupos mais expressivos foram:

- o Grupo Saraiva, formado pelas Editoras Saraiva, Atual e Formato;

- o Grupo Abril, dono das Editoras Ática e Scipione;

- as Editoras IBEP e a Companhia Editora Nacional;

- a FTD, dona da Editora Quinteto;

- o Grupo Prisa-Santillana, espanhol, dono das editoras Moderna, Objetiva e Salamandra;

- a Editora do Brasil. ${ }^{2}$

O faturamento das editoras e o volume do mercado de livros didáticos mostram claramente que é importante pensar a natureza múltipla desse tipo de livro: ou seja, ele deve atender a exigências didático-pedagógicas e também a demandas mercadológicas (Bittencourt, 2004). (2004:128):

Como salientam Sônia Regina Miranda e Tânia Regina de Luca

Cumpre destacar que para o segmento voltado para as compras do setor público importa menos a orientação metodológica ou a ideologia contida em uma coleção didática e mais a sua capacidade de vendagem e aceitação no mercado. Nesse contexto o livro didático assume claramente a sua dimensão de mercadoria, sujeita a múltiplas interferências em seu processo de produção e vendagem. 
Ainda de acordo com as autoras, a não aprovação de coleções de uma dada editora pode, a depender do porte da empresa, condená-la à falência, razão pela qual se assiste à formação de grandes conglomerados editoriais que podem lançar mais de uma coleção e assim se resguardar de uma eventual reprovação nos programas do governo.

Outro segmento do mercado de livros e materiais didáticos são os chamados "sistemas de ensino". Originários dos cursos pré-vestibulares, nascidos em geral na década de 1970, os sistemas de ensino passaram a produzir materiais didáticos que pretendiam cobrir todo o programa das disciplinas do currículo escolar. Assim, através de modelos fechados adquiridos pelas escolas, esses sistemas fornecem coleções de livros e materiais, modelos de avaliação e suporte pedagógico às escolas que os adquirem. Sem entrar no mérito das vantagens e desvantagens que os sistemas de ensino apresentam, o que é preocupante é o fato de passarem ao largo de qualquer avaliação. Trata-se de um número significativo de livros e apostilas que não contam com nenhum tipo de avaliação que possa atestar sua qualidade e pertinência. Destaque-se o fato de que também nas escolas privadas a aquisição de livros, em muitos casos, não leva em consideração as avaliações produzidas no âmbito do PNLEM.

Dessa forma, convém ressaltar a importância das avaliações feitas pelo MEC no sentido de fornecer um crivo para a escolha a ser feita pelos professores. Trata-se de uma tarefa extremamente complexa, mas que oferece uma visão crítica através de resenhas elaboradas por uma equipe especializada. Se, por um lado, os programas ainda apresentam deficiências estruturais, por outro, vêm mostrando ser uma maneira cada vez mais eficiente de pressionar o mercado, no intuito de fornecer obras pertinentes do ponto de vista formal e historiográfico.

\section{Dimensionamento dos mercados}

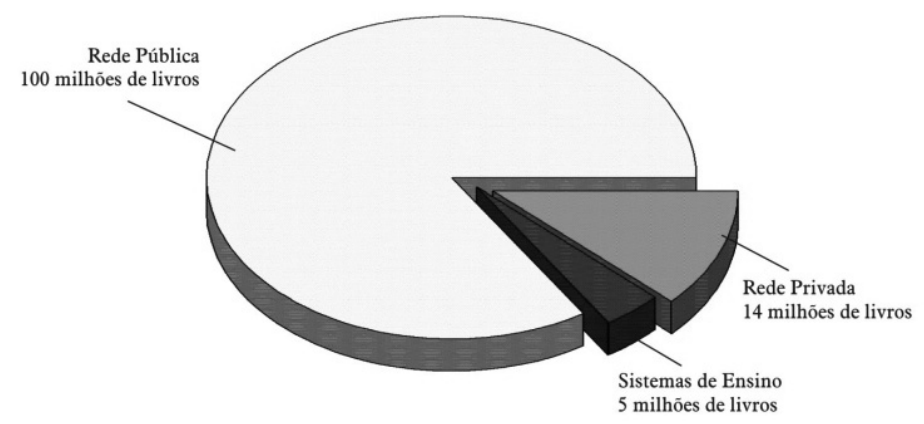

Fonte: PNLD e PNLEM 2008 


\section{Participação no Mercado de Livros Didáticos} (Fundamental I - $1^{\mathrm{a}}$ a $4^{\mathrm{a}}$ série)

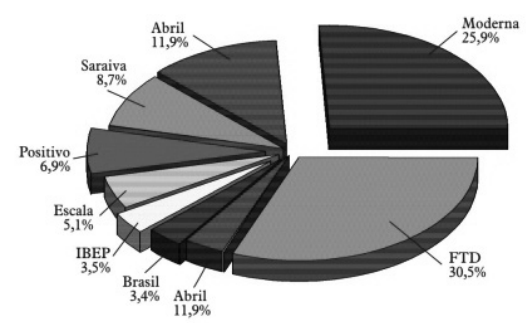

Fonte: PNLD e PNLEM 2008

\section{Participação no Mercado de Livros Didáticos} (Ensino Médio)

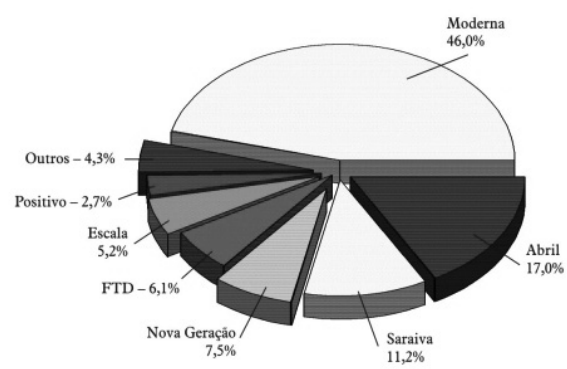

Fonte: PNLD e PNLEM 2008

\section{Participação no Mercado de Livros Didáticos} (Fundamental II - $5^{\mathrm{a}}$ a $8^{\mathrm{a}}$ série)

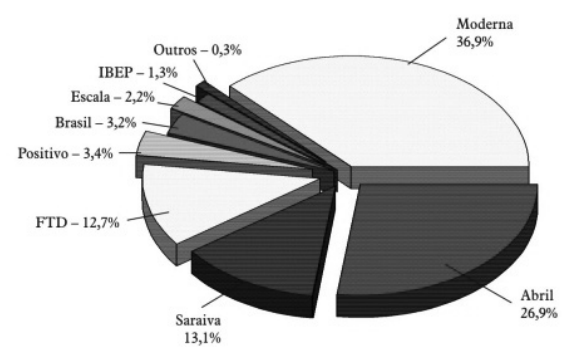




\section{Participações no Mercado Editorial \\ Principais grupos}

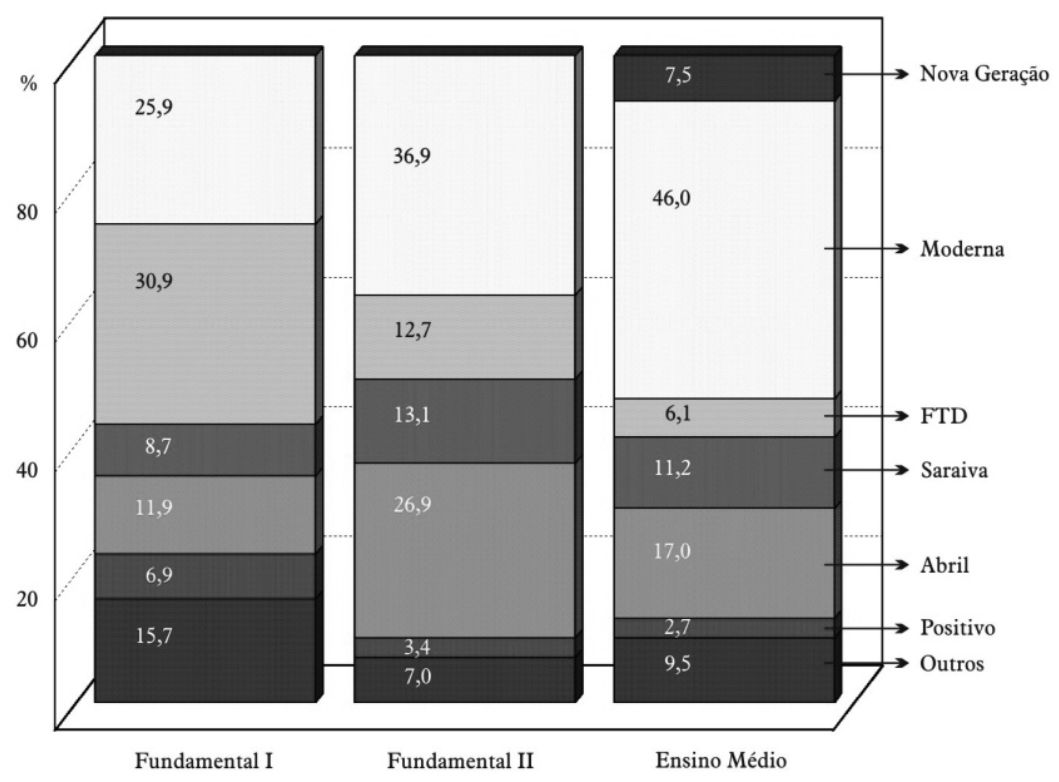

Fonte: PNLD e PNLEM 2008

\section{Percurso histórico das licenciaturas: o papel do professor}

A despeito das dificuldades, a qualidade dos livros e materiais tem sofrido uma melhoria expressiva. Mas "bons" livros necessariamente alteram a qualidade da educação? A nosso ver, os livros representam um papel significativo, porém não exclusivo, no processo de aprendizagem, estando, portanto, longe de responder sozinhos pela qualidade do ensino de história. Um ponto fundamental, mas que nem sempre tem recebido a devida atenção, é a formação dos professores.

O debate sobre o formato ideal para os cursos de licenciatura, sobretudo no que diz respeito à distribuição entre as disciplinas de formação pedagógica e de conteúdo, não constitui novidade. Na década de 1930, quando foi criado um dos primeiros cursos de formação de professores de história, na Universidade do Distrito Federal (UDF), já se discutiam essas questões. Buscava-se um equilíbrio entre as atividades de ensino e pesquisa de modo a produzir professores com 
uma sólida formação historiográfica e, ao mesmo tempo, com os recursos necessários para o exercício de suas atividades docentes.

Essa proposta, no entanto, não logrou êxito. Nas décadas seguintes, os cursos de graduação em história, que ficaram a cargo das Faculdades de Filosofia, Ciências e Letras, tiveram como preocupação formar apenas transmissores de conhecimento. Os graduados obtinham os títulos de bacharel e licenciado, mas na prática o destino da grande maioria era o magistério. Os depoimentos de Maria Yedda Linhares (1992) e Francisco Falcon (2001) demonstram com clareza essa orientação do curso da FNFi da Universidade do Brasil, que se manteria relativamente inalterada ao longo dos anos 1950 e 1960.

A instauração do regime militar trouxe mudanças significativas não somente para a vida política do país, mas também para a organização do sistema educacional. A Reforma Universitária estabelecida em 1968 com a Lei ${ }^{0}$ 5.540/68 implementou transformações que estreitavam os vínculos da educação superior com o mercado. A criação de cursos de curta duração, o aumento do número de vagas em instituições particulares e a organização em departamentos, a fim de gerar eficiência burocrática, foram algumas das medidas introduzidas.

O ensino básico foi alvo de uma nova estruturação com a legislação aprovada em 1971 (Lei n ${ }^{0}$ 5.692/71). Nela, a educação era entendida como uma ferramenta para o desenvolvimento econômico e para a manutenção da segurança nacional, de acordo com o vocabulário do regime militar. Por seu lado, formação do professor era enfocada através do estabelecimento de algumas medidas como o aproveitamento de graduados do ensino superior como docentes das disciplinas de formação profissional, a fixação de padrões de vencimentos relacionados à capacitação do professor, e a elaboração de critérios de avaliação (Saviani, 1997).

Naquele contexto, o treinamento de professores caracterizava-se pela introdução de elementos técnico-pedagógicos no ensino público, como a massificação de conteúdos através de livros didáticos, técnicas de estudo dirigido, novos contornos curriculares e conteúdos técnico-profissionalizantes. O objetivo era possibilitar o acesso a habilidades básicas, que consolidariam um contingente de profissionais minimamente capacitados para o ingresso no mercado de trabalho. Nesse sentido, é emblemática a instituição do curso que ficaria conhecido como "licenciatura curta", chamado pela Lei no 5.692 de licenciatura de primeiro grau, cuja função era formar professores para lecionar da $1^{\mathrm{a}}$ à $8^{\mathrm{a}}$ série.

No caso específico do ensino de história, a mudança mais significativa foi a criação de um nova licenciatura, denominada "estudos sociais", que reunia os conteúdos de história, geografia e organização social e política do Brasil. Os resultados dessas iniciativas não poderiam ter sido mais danosos, tanto para os cursos de licenciatura como para os alunos do ensino básico, que se deparavam com currículos inadequados e docentes mal preparados. A perda de uma identi- 
dade positiva pelos professores dessas áreas foi outra conseqüência dessas medidas. A proposta de conjugação entre ensino e pesquisa na formação de licenciados foi também completamente descartada.

Paralelamente a essas transformações no ensino, ocorreu a instalação e a expansão de programas de pós-graduação, sobretudo a partir da década de 1970. A comunidade acadêmica começava a propor novos termos para o debate sobre as diretrizes curriculares das graduações de história, delineando de forma mais clara a oposição entre a formação de professores e a de pesquisadores, entre a licenciatura e o bacharelado. $\mathrm{O}$ ingresso de novas gerações nos programas de pós-graduação nos anos 1970 e, posteriormente, nos quadros das universidades, trouxe sem dúvida uma melhor qualificação dos profissionais, cada vez mais voltados para pesquisas inovadoras e para o ensino da pós-graduação. No entanto, a priorização da carreira acadêmica e uma excessiva especialização temática dos objetos de investigação colocavam em um plano secundário a formação de docentes. A preocupação em formar alunos que fossem atuar como professores nos níveis médios e que deveriam receber conhecimentos que permitissem sua melhor preparação para o magistério ficava cada vez mais desvalorizada. Na prática, estabelecia-se paulatinamente uma separação radical entre os cursos de graduação e as Faculdades de Educação, responsáveis por ministrar os conteúdos pedagógicos.

Essas novas configurações das licenciaturas e do ensino foram, ao longo dos anos 1970, alvo de muitas críticas. Em 1986, foi publicado o Diagnóstico e avaliação dos cursos de história no Brasil, documento resultante dos trabalhos de um grupo de consultores convocados pela Secretaria de Educação Superior (SESu-MEC). O documento, elaborado após ampla consulta a diversas instituições, interpretava a Lei ${ }^{\circ} 5.692$ como parte da tentativa dos governos militares de descaracterizar o ensino de história e geografia para disseminar o ideário moral e cívico, questionava a existência dos estudos sociais e recomendava a supressão dos cursos recém-criados em todo o Brasil.

As discussões que se estenderam pela década de 1980 apontavam para a superação das concepções da legislação do regime militar. Nesse sentido, crescia a demanda por uma educação voltada para a formação de cidadãos, o que deveria ser refletido em todos os níveis de ensino e, especialmente, na formação de professores. A aprovação em 1996 de uma nova Lei de Diretrizes e Bases da Educação Nacional (Lei no 9.394/96), a partir do projeto apresentado ao Senado por Darcy Ribeiro, foi o auge desse processo de amplo debate social sobre a educação, iniciado principalmente com a redemocratização do país.

A nova LDB atribuiu responsabilidades sobre os diferentes níveis de ensino às três esferas governamentais (federal, estadual, municipal) e trouxe uma preocupação maior com a formação dos professores. Um dos grandes 
impactos da lei sobre a formação de professores deu-se com a determinação de um mínimo de 300 horas de duração para a disciplina "prática de ensino" na formação docente, mais uma expressão da relevância atribuída pela lei à experiência em sala de aula. Como resultado, alguns cursos de história procuraram apropriar-se da responsabilidade sobre esse novo contingente de horas, buscando integrar-se ao processo de formação de professores em vez de delegá-lo somente aos departamentos de educação. ${ }^{3}$

A partir da década de 1990 houve uma crescente introdução de instrumentos de avaliação em todos os níveis de ensino, iniciativa que vem permitindo um diagnóstico mais completo do sistema educacional brasileiro. Mas isso não implica a formação de consensos no que se refere ao formato das licenciaturas e, conseqüentemente, ao perfil do professor de história. Ainda permanece, nas discussões pós-LDB (1996), a dicotomia entre ensino e pesquisa; mais especificamente falando, entre licenciaturas e bacharelados. A necessidade de superar 0 dilema entre ensino e pesquisa e a a preocupação em formar um professor-pesquisador aparecem largamente tanto nos documentos governamentais quanto nas propostas curriculares dos cursos e das entidades docentes (Saviani, 1997; Ricci, 2003).

No caso dos cursos de história, o que se verifica é uma constante preocupação com a integração entre as duas formações: a do pesquisador e a do professor. Essa preocupação, contudo, nem sempre se reflete na organização curricular dos diferentes cursos, nos quais as disciplinas de bacharelado são freqüentemente somadas às disciplinas pedagógicas, oferecidas e geridas pelas Faculdades de Educação para compor o currículo da licenciatura.

De uma maneira geral, apesar da profusão de debates e da discussão pedagógica produzida a partir de 1996, na enorme maioria dos cursos de licenciatura em história persiste a valorização do pesquisador em detrimento do professor e a separação entre academia e ensino. Nas universidades de maior prestígio, espaços em que deveríamos encontrar professores qualificados para exercer o magistério, freqüentemente nos deparamos com a resistência dos docentes às discussões sobre o ensino da disciplina. Postula-se a necessidade de iniciativas que levem à integração entre os dois mundos, que reconhecem a importância de uma real aproximação, mas ainda não se encontraram os caminhos efetivos para tanto.

Um último ponto que merece destaque é a má remuneração dos docentes dos ensinos fundamental e médio, o que contribui para afastar ainda mais docência e pesquisa. A carreira de professor implica uma extenuante jornada de trabalho, tornando-se cada vez menos atrativa para os recém-formados nas graduações de história. Não raro, os alunos mais bem qualificados direcionam suas carreiras para a pós-graduação, afastando-se completamente da atividade docente. 
Essa situação é verificável em todas as áreas, mas é especialmente dramática no caso da história, onde há uma oferta de profissionais que permanecem no campo pela impossibilidade de encontrar alternativas mais rentáveis.

\section{O ensino de história}

Diante do complexo quadro que envolve bons profissionais, livros de qualidade e, sobretudo, uma relação dialógica entre academia e ensino, é preciso ressaltar a importância de se ver os problemas relacionados aos manuais didáticos como apenas uma parte de uma questão muito maior. Não é possível pensar o livro didático em separado de questões como as levantadas acima. Não deixa de ser significativo que os professores acadêmicos participem apenas episodicamente da feitura de manuais didáticos, e que docentes dos ensinos fundamental e médio repitam interpretações superadas para os acadêmicos. $\mathrm{O}$ recente debate na grande imprensa põe em foco uma questão: qual a importância do historiador em toda essa discussão? Apesar das diretrizes dadas pelos PCNs, é preciso salientar que a elaboração de um material de síntese como o livro didático implica grandes dificuldades e desafios. Em primeiro lugar, o extenso currículo de história impõe um alargado e aprofundado conhecimento do conteúdo. Some-se a isso a necessidade de síntese e clareza dos textos, tendo em vista um público heterogêneo de alunos e professores. Diante das várias possibilidades de leitura, o texto didático deve procurar minimizar as ambigüidades. Cria-se, assim, uma grande dificuldade para os autores: como compatibilizar uma visão crítica do passado e a necessidade de síntese, clareza e objetividade que as obras colocam? $\mathrm{O}$ que significa uma visão crítica do passado?

A idéia de uma história "crítica" e "progressista" esbarra, não raro, em interpretações maniqueístas nas quais, por exemplo, a história brasileira é definida como uma história de exploração, seja de Portugal sobre a colônia, seja das elites sobre as classes populares, seja dos Estados Unidos sobre o Brasil. Esse tipo de visão reduz a informação histórica à denúncia, e a explicação dos fatos à luta de classes, à revolução ou à ação engajada.

Entendemos que o livro didático, em lugar de oferecer uma visão "crítica" a priori, deve desenvolver a capacidade crítica do aluno. A crítica de documentos e de diferentes interpretações, parte do métier do historiador (Bloch, 2002), passa pelo confronto de discursos muitas vezes contraditórios e de interpretações distintas. O ensino da história não deve ser feito pela escolha de ideologias à esquerda ou à direita, mas pela problematização dos discursos. Questões como o papel da história e o método inerente à disciplina exigem grande cuidado.

Se a história é a "ciência do homem no tempo", é preciso salientar que uma tarefa imprescindível ao livro didático é fornecer ao aluno subsídios para o 
entendimento das várias temporalidades que o conhecimento histórico envolve. Esse nos parece ser um aspecto fundamental a ser levado em conta nos manuais, mas que freqüentemente é desrespeitado em nome de aproximações temporais indevidas. $\mathrm{O}$ conceito de democracia hoje, por exemplo, não é igual ao conceito de democracia na Grécia antiga.

A falta consciência muitas vezes dá lugar a visões anacrônicas do passado, e não raro, em nome de aproximações mais “didáticas”, os manuais esbarram na indistinção temporal. Já a consciência de um processo histórico que se desenrola ao longo do tempo ajuda a entender, por exemplo, a formação do território brasileiro. Construído ao longo de séculos, através de várias negociações, resultado de acasos e disputas, o Brasil e seu território no século XXI não são a mesma sucessão de enclaves fragmentados ao longo da costa da América do Sul do século XVI. No entanto, é freqüente encontrar nos livros didáticos termos como "brasileiro", "literatura nacional", "país", entre outros, referindo-se ao século XVI.

Esses vários impasses fazem com que muitos autores de obras didáticas trilhem o caminho simplificado e anódino de nem fazer grandes reestruturações, nem abandonar certos esquemas aceitos e altamente vendáveis. Diante do quadro aqui esboçado, seria útil refletirmos sobre a importância do ensino de história. Quais as funções e o alcance do livro didático? Que espírito “crítico" o livro deve desenvolver? Qual o papel do professor nesse complexo sistema? Qual o papel do historiador, enquanto produtor de conhecimento, na feitura de materiais didáticos?

Notas

1. Segundo Carlos Alberto Sardenberg (2007): "A história do PT é o exemplo prático dessa contradição. Passou a vida defendendo o socialismo, condenando o neoliberalismo, para chegar ao poder e verificar que não há outro caminho senão o capitalismo globalizado."

2. Segundo Célia Cassiano (2007), apenas a Editora do Brasil é independente, sendo que as demais passaram a fazer parte de grandes grupos editoriais.
3. Posteriormente, foi homologado um parecer do Conselho Nacional de Educação fixando diretrizes para a formação de professores da educação básica em que a carga horária mínima para a prática como componente curricular foi elevada para um total de 400 horas. Ver Parecer CNE/CP 28/2001, homologado em 17 de janeiro de 2002 e publicado no Diário Oficial da União em 18 de janeiro de 2002. 
Referências bibliográficas

BITTENCOURT, Circe Maria Fernandes. 2004. Autores e editores de compêndios e livros de leitura (1810-1910). Educação e Pesquisa. São Paulo, v. 30, no 3, dez. p. 475-491.

BLOCH, Marc. 2002. Apologia da história ou o ofício do historiador. Rio de Janeiro: Jorge Zahar.

CASSIANO, Célia Cristina de Figueiredo. 2007. Mercado do livro didático no Brasil: do Programa Nacional do Livro Didático à entrada do capital internacional espanhol (1985 a 2007). São Paulo, USP (Tese de Doutorado).

FALCON, Francisco J. C. 2001. História e historiografia nos anos 50 e 60 do ponto de vista da cadeira de História Moderna e Contemporânea da Faculdade Nacional de Filosofia. In: SILVA, Francisco Carlos Teixeira da (org.). Conceitos sobre história e educação. Rio de Janeiro: Mauad/Faperj. p. 599-612.

KAMEL, Ali. 2007. O que ensinam às nossas crianças. $O$ Globo,18/9.
LINHARES, Maria Yedda. 1992. Entrevista a Marieta de Moraes Ferreira. Estudos Históricos, Rio de Janeiro, vol. 5, $\mathrm{n}^{\circ}$ 10, p. 216-236.

MIRANDA, Sonia Regina \& LUCA, Tânia Regina de. 2004. O livro didático de história hoje: um panorama a partir do PNLD. Revista Brasileira de História. São Paulo, v. 24, $\mathrm{n}^{\circ} 48$, p. 128.

RICCI, Cláudia Sapag. 2003. A formação do professor e o ensino de história. São Paulo, USP (Tese de Doutorado).

SARDENBERG, Carlos Alberto. 2007. As elites socialistas. $O$ Globo, 20/9.

SAVIANI, Demerval. 1997. A Nova Lei da Educação: $L D B$, trajetória, limites e perspectivas. Campinas: Editora Autores Associados.

SCHMIDT, Mário. 2006. Nova história crítica. São Paulo: Nova Geração Cultural.

\section{Resumo}

Este artigo discute a produção de material didático de história. Reflete sobre alguns debates recentes, focalizando a pertinência da escolha de conteúdos, e faz uma breve análise do mercado editorial e seu posicionamento na venda de obras para o PNLD e o mercado privado. O texto levanta algumas questões ligadas ao processo de formação de professores e aos cursos superiores de história, que em geral privilegiam a pesquisa em detrimento do ensino, o que dificulta a definição de um formato coerente para as licenciaturas.

Palavras-chave: ensino de história, produção de materiais didáticos, formação de professores 


\begin{abstract}
This article discusses the production of history text-books in Brazil. It reflects on some recent discussions focusing on the pertinence of their contents, and it presents a short analysis of Brazilian editorial market and the sales of text-books both to the national authority who will distribute them among public schools and to the private market. The article raises a few questions about the qualification of teachers and the structure of History courses, which generally privilege research instead of teaching, making it difficult to establish a coherent structure for teacher training courses.

Key words: History teaching, production of text-books, teacher training courses
\end{abstract}

\title{
Résumé
}

Larticle porte sur production de manuels d'Histoire au Brésil. Il refléchit sur les discussions actuelles sur la pertinence de leur contenu et présente une brève analyse du marché éditorial Brésilien et des ventes de ce genre de livres pour l'autorité nationale qui les distribue parmi les écoles publiques et pour le marché privé. On pose aussi quelques questions sur le processus de qualification des enseignants, ainsi que sur la structure des cours d'Histoire, qui en général privilégient la recherche plutôt que l'enseignement, ce qui empêche l'établissement d'une structure cohérente.

Mots-clés: enseignement de l'Histoire, production de manuels, formation des professeurs 